\title{
Screeningul neonatal pentru fenilcetonurie şi hipotiroidism congenital: rezultatele Centrului Cluj, 2011-2015
}

\author{
Carmen Costache', Andreea Faur ${ }^{2}$, Antoniea Popescu ${ }^{3}$ \\ ${ }^{1}$ Disciplina de Microbiologie, \\ Universitatea de Medicină şi Farmacie „Iuliu Haţieganu“, Cluj-Napoca, România \\ ${ }^{2}$ Laboratorul de screening neonatal fenilcetonurie şi hipotiroidism, \\ Spitalul Clinic Judeţean de Urgenţă Cluj (SCJUC), Cluj-Napoca, România \\ 3Pediatrie-Neonatologie, Universitatea de Medicină şi Farmacie „Iuliu Haţieganu“ Cluj-Napoca, \\ România
}

\begin{abstract}
REZUMAT
Obiective. Scopul studiului nostru a fost de a evalua starea actuală a screeningului neonatal pentru două erori înnăscute de metabolism, fenilcetonuria şi hipotiroidismul congenital (SN-PKU-CH), în partea de nord-vest a României, în centrul regional Cluj (CRCJ), unul dintre cele cinci centre de screening din țară responsabil pentru screeningul din 7 județe.

Material şi metodă. Studiul descriptiv transversal este bazat pe datele obținute la screeningul a 101.739 de nou-născuți în perioada 2011-2015. Screeningul se efectuează pentru 2 boli rare: fenilcetonurie (PKU) şi hipotiroidism congenital $(\mathrm{HC})$ din spoturi de sânge recoltate pe hârtie de filtru standardizată (DBS). Concentrația fenilalaninei (Phe) şi a hormonului de stimulare tiroidiană (TSH) este măsurată prin intermediul unui test imunofluorimetric. Nou-născuții cu valori peste limitele superioare ale testelor (TSH $>18 \mu \mathrm{Ul} / \mathrm{ml}$ sau Phe $>3 \mathrm{mg} /$ dl) sunt rechemați pentru evaluare clinic-biologică şi confirmați prin dozarea free-T4 (fT4) sau Phe plasmatică (cromatografie în strat subțire cuplată cu video-densimetrie) înainte de ziua 21 de la naştere, pentru prevenirea encefalopatiei.

Rezultate. Au fost confirmate 10 cazuri cu PKU ( 1/10.000), 6 cu hiperfenilalaninemie (HPA) şi 10 cu HC, toate beneficiind de tratament. Nici unul dintre copii (1-5 ani) nu a dezvoltat handicap neuro-psihomotor fenilpiruvic. Totalul de nou-născuți a fost de 115.779 , iar 101.739 au fost testați $(87,87 \%)$, ceea ce arată că 14.040 nu au fost testați $(13,80 \%)$. Cea mai frecventǎ mutație la cazurile confirmate a fost R408W.

Discuții. Județele în care implementarea programului este deficitară sunt: Maramureş $4.811(20,26 \%)$, Bihor $3.349(11,33 \%)$ şi Sibiu unde sunt 6.537 (30,65\%) de nou-născuți netestați, existând maternități în care programul de screening nu este aplicat.

Concluzii. Procentul mare de nou-născuți netestați face posibilă apariția cazurilor cu defecte neurologice ireversibile. O mai bună organizare a recoltării şi transportului, comunicarea către laboratorul de screening a cazurilor confirmate şi finanțarea analizei genetice la aceste cazuri ar conduce la eficientizarea programului. Numărul de cazuri confirmate susține dezvoltarea programului în viitor cu cuprinderea eventual şi a altor boli rare congenitale.
\end{abstract}

Cuvinte cheie: screening neonatal, fenilcetonurie (PKU), hipotiroidism congenital, hiperfenilalaninemie (HPA)

\section{INTRODUCERE}

Programele de screening neonatal (SN-PKUCH) care utilizează DBS (dry blood spot) au fost înființate pentru prima dată în 1960 de către Dr. Robert Guthrie. În prezent, SN-PKU-CH este o practică bine stabilită în țările cele mai dezvoltate la nivel mondial, în timp ce în țările în curs de dezvoltare, care reprezintă cea mai mare parte din Eu- ropa de sud-est, este mai puțin uniform pus în aplicare (1).

În partea de nord-vest a României, programul de SN-PKU pentru fenilcetonurie (PKU) a început în 1 decembrie 1978 în Cluj, adresându-se numai nounăscuților din județul Cluj. Alte județe au fost introduse în SN-PKU în perioada 1995-2000, când au fost testați nou-născuții de la 25 de maternități din 
județele Cluj, Bihor, Sălaj, Maramureş şi Sibiu. În anul 2000 a fost adăugat în programul SN-PKU$\mathrm{CH}$ screeningul pentru hipotiroidism congenital (HC). Pentru o scurtă perioadă de timp (3 ani), maternităţile din județele Hunedoara şi Harghita au trimis probe la centrul regional Cluj (CRCJ). Începând cu 1 ianuarie 2015, 3 județe au fost transferate de la centrul Bucureşti la CRCJ: Harghita, Sălaj şi Satu-Mare. În prezent, CRCJ efectuează screeningul cu probe primite de la 35 de maternităţi situate în 7 județe. În anul 2011 a fost înființat în România registrul naţional PKU.

Rezultatele dintr-un sondaj şi studii complementare $(2,3)$ au evidențiat faptul că, deşi larg răspândit, SN-PKU-CH nu este încă realizat la toți nou-născuții, în unele țări din Europa (inclusiv Bulgaria şi România) cu programe de SN-PKU-CH implementate, până la 10\% din nou-născuți nefiind testați (1). Oricum, în ultimii 4 ani numărul de nounăscuţi care scapă testării a scăzut semnificativ.

\section{OBIECTIVE}

Scopul acestui studiu este de a prezenta rezultatele programului de SN-PKU-CH pentru boli rare, PKU şi HC, la nivelul CRCJ: numărul şi procentul de nou-născuți testaţi vs. netestați în fiecare județ, în fiecare an; rata cazurilor pozitive la screening şi rata cazurilor confirmate de PKU, HPA (hiperfenilalaninemie) şi HC în fiecare județ. În acelaşi timp, vom prezenta problemele cu care ne confruntăm în organizarea şi punerea în aplicare a acestui program la nivelul centrului nostru regional.

\section{METODE}

Studiul este unul descriptiv transversal. Materialul este reprezentat de cohorta nou-născuților testați în perioada 2011-2015 din maternităţile situate în nord-vestul țării, 4 județe (Cluj, Bihor, Maramureş, Sibiu) şi de la alte 3 județe transferate la centrul nostru începând cu data de 1 ianuarie 2015 (Satu-Mare, Harghita şi Sălaj). Numărul de nounăscuți testați din aceste maternități a fost 101.739.

Pachetul de screening pentru tulburările congenitale include 2 boli: PKU şi hipotiroidismul congenital HC.

Metodele efectuate în centrul nostru sunt metoda cu ninhidrină pentru PKU şi fluorescența rezolvată în timp (fluoroimunoanaliza) pentru TSH (hormonul de stimulare tiroidiana).

Testele sunt efectuate semi-automat, cu o linie dedicată care utilizează un puncher automat, un incubator cu agitator pentru microplăci, un washer şi un cititor de fluorescență (Anthos Labtec Instruments, Salzburg - Austria, Zenyth 3100 detector multimode). Cititorul foloseşte o măsurătoare cu fluorescență rezolvată în timp (TRF) pentru cuantificarea TSH-ului şi a intensității fluorescenței de top pentru PKU. Unitățile de fluorescență măsurate sunt transferate on-line pe computer şi calculate în termeni de concentrații.

Metoda cu ninhidrină pentru PKU se bazează pe creşterea fluorescenței fenilalanină - ninhidrină, produsul de reacție a dipeptidei L-leucil-L-alanină. Metoda măsoară fenilalanina cantitativă în prezența altor aminoacizi, folosind o lungime de undă de $390 \mathrm{~nm}$ pentru excitaţie şi o lungime de undă de $486 \mathrm{~nm}$ pentru emisie (Kit Neonatal PhenyalanineNP-1000/NP-4000).

Analiza imunofluorometrică pentru hTSH este o analiză fluoroimunometrică bazată pe tehnica sandvici directă în care doi anticorpi monoclonali (de la şoareci) sunt îndreptaţi către situsurile antigenice distincte ale hormonului (DELFIA neonatal hTSH). Standardele, controalele şi probele de testare conținând TSH reacţionează simultan cu anticorpii monoclonali imobilizaţi către situsul antigenic specific şi anticorpi monoclonali marcați cu europiu (către un situs antigenic diferit situat parțial pe subunitatea $\beta$ ). Ionii de europiu din anticorpul marcat sunt disociaţi în a doua etapă şi formează chelaţi fluorescenți. Fluorescența în fiecare godeu este apoi măsurată, fiind proporțională cu concentrația de TSH în probă $(4,5)$.

În screening valorile limită sunt utilizate cu scopul de a detecta rezultatele anormale, care disting între nou-născuții eutiroidieni şi hipotiroidieni (9$18 \mu \mathrm{U} / \mathrm{ml}$ eutiroidieni, hipotiroidiene $>18 \mu \mathrm{U} / \mathrm{ml}$, (6) în timp ce pentru PKU valorile limită sunt între 2,1-3 $\mathrm{mg} / \mathrm{dl}$, iar probele prezumtiv pozitive sunt cele care depăşesc $3 \mathrm{mg} / \mathrm{dl}$.

Pacienții cu valori limită sunt rechemați urgent pentru teste de confirmare. Testul de confirmare este efectuat prin examinare clinică, măsurarea nivelului seric al fT4 (free T4) şi TSH pentru HC, respectiv dozarea Phe $(5 \mathrm{ml})$ recoltat pe heparină, la 3 ore după ultima masă a sugarului, prin metoda cromatografiei în strat subțire cuplată cu video densitometrie pentru PKU, pacienții cu valori ale Phe mai mici de $8 \mathrm{mg} / \mathrm{dl}$ fiind diagnosticați cu HPA, iar cei cu valori mai mari fiind diagnosticaţi cu PKU.

\section{REZULTATE}

În prezent, SN-PKU-CH se desfăşoară în 35 de maternități din 7 județe: Cluj, Bihor, Maramureş, Sibiu, Satu-Mare, Sălaj, Harghita (Fig. 1). 


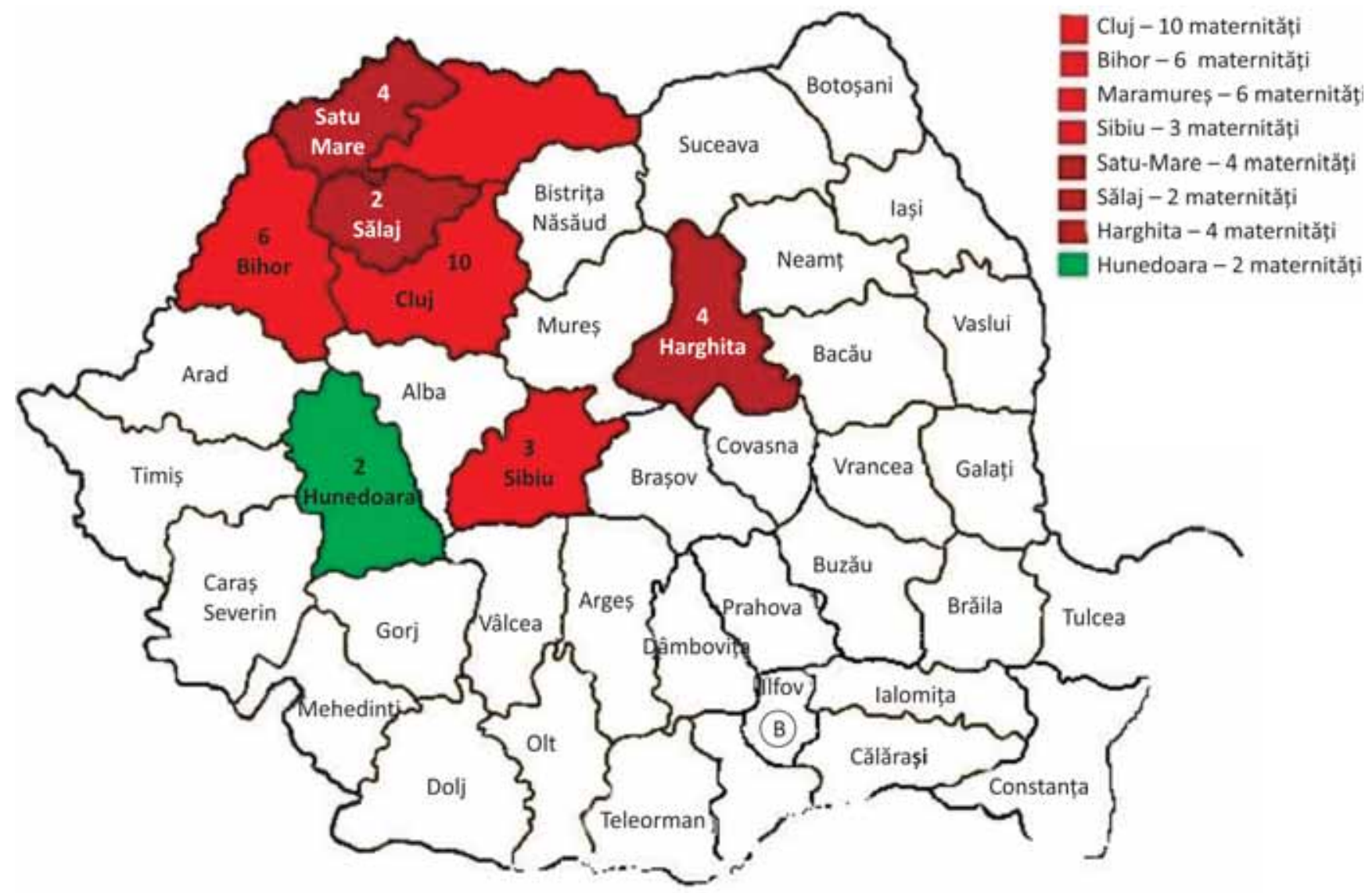

FIGURA 1. Cronologia PNS - introducerea pentru PKU şi HC în regiunea de nord-vest a României, $1978-2015$ 1978 - Cluj

1995-2000 - Cluj, Bihor, Sălaj, Maramureş şi Sibiu

2008-2010 - Cluj, Bihor, Maramureş, Sibiu, Hunedoara şi Harghita

2011-2014 - Cluj, Bihor, Maramureş şi Sibiu

2015 - Cluj, Bihor, Maramureş, Sibiu, Satu-Mare, Sălaj, Harghita

Dintr-un total de 115.779 de nou-născuţi, 101.739 au fost testați (87,87\%), iar 14.040 (12,13\%) nu au fost testaţi. Numărul total al nou-născuților din fiecare județ a fost obținut din statisticile Direcțiilor de Sănătate Publică (DSP). Numărul şi rata de nounăscuți testați şi netestați pe județ şi pe an este prezentată în Tabelele 1 şi 2.
Din numărul total de nou-născuţi, la screeningul PKU au fost 227 de teste pozitive, necesitând confirmare. Au fost trimise scrisori către părinți pentru a aduce copilul pentru evaluarea clinică şi biochimică şi s-au efectuat teste de confirmare. S-au confirmat 10 cazuri cu PKU, în timp ce 6 cazuri au fost diagnosticați cu HPA. Rata de confirmare a fost de

TABELUL 1. Număr nou-născuți testați vs. netestați pe județ

\begin{tabular}{|l|c|c|c|c|c|}
\hline Județ & $\begin{array}{c}\text { Nr. } \\
\text { nou-născuți vii }\end{array}$ & $\begin{array}{c}\text { Nr. } \\
\text { nou-născuți testați }\end{array}$ & $\begin{array}{c}\text { Rată testați } \\
\%\end{array}$ & $\begin{array}{c}\text { Nr. nou-născuți } \\
\text { netestați }\end{array}$ & $\begin{array}{c}\text { Rată netestați } \\
\%\end{array}$ \\
\hline Sibiu & 21.329 & 14.792 & 69,35 & 6.537 & 30,65 \\
\hline Maramureș & 23.745 & 18.934 & 79,74 & 4.811 & 20,26 \\
\hline Bihor & 29.548 & 26.199 & 88,67 & 3.349 & 11,33 \\
\hline Cluj & 32.693 & 34.449 & $*$ & - & $*$ \\
\hline Satu-Mare & 3.490 & 2.522 & 72,26 & 968 & 27,74 \\
\hline Harghita $^{\text {b }}$ & 3.041 & 2.949 & 96,97 & 92 & 3,03 \\
\hline Sălaj $^{c}$ & 1.933 & 1.894 & 97,98 & 39 & 2,02 \\
\hline
\end{tabular}

*mamele din mai multe judeţe vin pentru a naște în Cluj, în timp ce copiii sunt înregistraţi pe baza buletinului părinţilor în judeţul de reședinţă (vezi discuţii)

a,b,c - județe transferate de la centrul București din 1 ianuarie 2015 
TABELUL 2. Număr nou-născuți testați vs. netestați pe an

\begin{tabular}{|l|c|c|c|c|c|}
\hline Anul & $\begin{array}{c}\text { Nr. nou-născuți } \\
\text { vii }\end{array}$ & $\begin{array}{c}\text { Nr. nou-născuți } \\
\text { testați }\end{array}$ & $\begin{array}{c}\text { Rată testați } \\
\%\end{array}$ & $\begin{array}{c}\text { Nr. nou-născuți } \\
\text { netestați }\end{array}$ & $\begin{array}{c}\text { Rată netestați } \\
\%\end{array}$ \\
\hline 2011 & 20.580 & 19.320 & 93,87 & 1.260 & 6,13 \\
\hline 2012 & 21.119 & 17.988 & 85,17 & 3.131 & 14,83 \\
\hline 2013 & 21.029 & 18.328 & 87,15 & 2.701 & 12,85 \\
\hline 2014 & 21.987 & 19.128 & 86,99 & 2.859 & 13,01 \\
\hline 2015 & 34.554 & 26.975 & 78,06 & 7.579 & 21,94 \\
\hline TOTAL & 115.779 & 101.739 & 87,87 & 14.040 & 12,13 \\
\hline
\end{tabular}

$16 / 227=7,05 \%$ pentru PKU şi HPA. Incidența pentru PKU în centrul nostru a fost de aproximativ 1/11.600 de nou-născuți, dar aproape se dublează dacă includem cazurile cu HPA (6). Confirmarea diagnosticului s-a realizat la toate cazurile în timpul util precizat în literatura de specialitate (maximum 21 de zile de la naştere) pentru introducerea tratamentului dietetic specific pentru prevenirea efectelor negative asupra sistemului nervos central (7).

Valorile limită pentru $\mathrm{HC}$ au fost depăşite de 242 de nou-născuți şi s-au confirmat 10 cazuri cu HC (Tabelul 3).

Nu a existat nici o diferență semnificativă între numărul de cazuri confirmate în funcție de județul de proveniență, aşa cum se arată în Tabelul 4.

TABELUL 3. Rata cazurilor confirmate din cele pozitive la screening

\begin{tabular}{|l|c|c|c|}
\hline $\begin{array}{l}\text { Boala } \\
\text { congenitală }\end{array}$ & $\begin{array}{c}\text { Probe pozitive } \\
\text { la screening }\end{array}$ & $\begin{array}{c}\text { Cazuri } \\
\text { confirmate }\end{array}$ & $\begin{array}{c}\text { Rata cazurilor } \\
\text { confirmate } \\
\%\end{array}$ \\
\hline PKU & 227 & 10 & 4,40 \\
\hline HPA & 227 & 6 & 2,64 \\
\hline HC & 242 & 10 & 4,13 \\
\hline
\end{tabular}

TABELUL 4. Cazuri confirmate pe județ

\begin{tabular}{|l|c|c|c|}
\hline Județ & PKU & HPA & CH \\
\hline Cluj & 2 & 4 & 10 \\
\hline Bihor & 4 & 0 & $*$ \\
\hline Maramureș & 4 & 2 & $*$ \\
\hline
\end{tabular}

* Nu ne-au fost comunicate rezultatele testelor de confirmare.

\section{DISCUȚII}

Acesta este primul studiu care a evaluat screeningul PKU şi HC pentru o perioadă de cinci ani, în 7 județe cu un total de 35 de maternități. În România există cinci centre de SN-PKU-CH situate în: Bucureşti, Cluj-Napoca, Timişoara, Iaşi şi TârguMureş, acesta fiind cel mai mare număr de centre/ țară din sud-estul Europei. Numărul mare de centre în comparație cu alte țări din Europa (una sau două), se explică prin faptul că în România este întâlnit cel mai mare număr de nou-născuți, comparativ cu toate celelalte țări din regiune (1).
Testul screening este gratuit pentru familie, costul per test $(2,5 \times 2=5$ euro $)$ fiind asigurat din bugetul alocat de Ministerul Sănătătii prin Programului Naţional de Screening Neonatal.

Confirmarea cazurilor este realizată în alt laborator aparținând SCJUC.

Tratamentul dietetic şi monitorizarea cazurilor confirmate se realizează în Clinica Pediatrie III. În acest moment, există 36 de pacienți copii cu PKU (o parte diagnosticați anterior perioadei prezentate) care primesc tratament dietetic şi sunt monitorizați de către pediatru. Majoritatea acestor pacienți trimit în laboratorul nostru un DBS pe săptămână sau o dată pe lună.

Problema cea mai critică este screeningul incomplet al nou-născuților din mai multe județe. Procentul de nou-născuți netestați la nivelul CRCJ este de $12,13 \%$, fiind îmbunătățit față de datele raportate din sud-estul Europei în 2014 şi $2015(1,4)$. Nou-născuții netestați sunt omişi de la diagnostic. Pe de altă parte, există laboratoare private care oferă o gamă largă de teste pentru diagnosticarea precoce a tulburărilor congenitale la care părinții se pot adresa în mod independent. Este la bunul arbitru al părinţilor comunicarea acestor date către centrul de screening, astfel încât în evidențele noastre aceşti copii pot figura ca fiind netestați, dar de fapt testarea lor a fost realizată în sistemul privat. Chiar dacă nu avem o comunicare cu privire la numărul de nou-născuți testați de către aceste laboratoare, cei care au fost diagnosticați cu PKU au primit tratamentul dietetic specific, respectiv tratamentul hormonal celor cu $\mathrm{CH}$, şi sunt monitorizați în cadrul programului național. Nou-născuții care au fost diagnosticaţi cu HPA nu necesită tratament, deficitul enzimatic fiind minor. Din cunoştinţele noastre, în CRCJ nu există nici un caz diagnosticat între 2011-2015 de la o altă sursă decât laboratoarele din cadru programului național (Laboratorul de Screening Neonatal şi Laboratorul de Explorări Genetice din SCJU-Cluj).

O altă problemă importantă este de a face o corespondență între locul în care a avut loc naşterea, respectiv testarea şi locul în care naşterea este ra- 
portată de către DSP (multe femei care locuiesc în alte județe vin să nască la Cluj). Această inadvertență a dus la situația raportată în Tabelul 1 pentru județul Cluj, unde numărul de nou-născuți este mai mic decât numărul testatelor efectuate. În acelaşi timp, putem specula că diferența de nou-născuți (1.756) testaţi în Cluj poate fi o parte din nou-născuții clasificați netestați în județul lor de reşedință (de exemplu, Sibiu cu 6.537 (30,65\%), Maramureş cu 4.811 (20,26\%) şi Bihor 3.349 (11,33\% - Tabelul 1). În acest sens, organizarea programului la nivel național şi județean ar trebui îmbunătățit deoarece în acest moment există două maternități din Sibiu, care nu aplică programul de screening ( $~ 830$ nounăscuți/an).

Pentru ameliorarea raportărilor în acest program propunem instituirea obligativității informării de către orice laborator (de stat sau privat) a centrului de screening privitor la efectuarea de teste screening sau de confirmare care legate de cele două afecțiuni metabolice acoperite de către programul național.

Calitatea probelor primite de către laboratorul de screening este o altă problemă cu care ne confruntăm. Calitatea proastă a 5,40\% din probe se datorează colectării/transportului incorect ceea ce conduce la rezultate fals-pozitive şi creşterea numărului de teste de confirmare.

Detectarea anomaliilor genetice în cazurile diagnosticate nu sunt acoperite de programul naţional. Părinţii se pot adresa laboratoarelor private pentru testare, dar costul testului este prohibitiv pentru un mare număr de familii (598-700 de euro). Cu toate acestea, avem rezultatul în ceea ce priveşte profilul genetic de la trei cazuri din cele 16 cazuri confirmate. Toate cazurile au avut mutația $\mathrm{R} 408 \mathrm{~W}$, cea mai frecventă mutație asociată cu PKU în populația noastră $(8,9)$ iar unul dintre ei a avut mutația S350Y, de origine paternă, pentru care nu se cunosc asocieri.

\section{CONCLUZII}

Numărul mare de nou-născuți netestați face posibilă apariția cazurilor cu tulburări neurologice ireversibile. Toate maternitățile din județele arondate centrelor ar trebui să colecteze şi să trimită probe la laboratorul de screening.

Absența comunicării de la cazurile confirmate, eventual, în alte județe nu permit o gestionare adecvată a datelor cu privire la eficiența programului de screening.

Organizarea corectă a colectării probei şi transportul către laborator va permite diagnosticarea precoce (screening si confirmare).

Introducerea finanțării analizei genetice în costurile acoperite de programul de screening şi management al cazurilor confirmate ar permite caracterizarea genetica a cazurilor în aria noastră geografică.

Numărul de cazuri confirmate pledează pentru dezvoltarea viitoare a programului de SN-PKU$\mathrm{CH}$, cu introducerea altor boli congenitale rare. 